\title{
15. Challenges in Engaging Citizens as Partners in the Community Sector
}

\author{
Yehudi Blacher
}

I am currently the Secretary of the Department of Planning and Community Development in Victoria, but have previously been associated with many state government agencies, including the Department of Premier and Cabinet, the Department of Human Services, and the Department for Victorian Communities.

My contribution to this volume primarily concerns the use of surveys as part of a process of citizen engagement. I will illustrate this by focusing on two surveys and, then, put them in the broader context of the range of engagement processes that my department undertakes.

I will begin, though, by setting some context for the department. The Victorian Department of Planning and Community Development was established in 2007 through the amalgamation of what was then the planning section in the Victorian government with the Department for Victorian Communities, which itself was established in 2002. Following the 2010 Victorian election, some of our responsibilities were transferred to other agencies, and other responsibilities were given to us. As a result we now have responsibility for the portfolios of land use planning, regional and community development, the regulation of local government, and sport and recreation, Aboriginal affairs, and veterans affairs. We have approximately 1000 staff, and we report to five ministers, the lead minister being the deputy premier.

The functions of our department have at their core the provision of support for the creation of strong, resilient, and effectively functioning communities. When the Department for Victorian Communities was established in 2002, it was the first time in Australia, and I think internationally, that there was a department created specifically for that purpose.

From the start we have been keen to engage directly with people in their communities about policy development and service delivery, and one of the ways we continue to do this is through surveys, but, over time, we have also utilised a large number of different engagement mechanisms. Apart from surveys, these have included regular community meetings, and new governance structures like regional management forums. Furthermore, in a structural sense, we have located our staff in communities to be direct conduits, brokers and facilitators between citizens, community organisations and government. 
Let me now give two specific examples of our surveys. From the beginning, we recognised that the Department needed to gather real data on what people valued in their communities and on how well these aspirations were being met. In partnership with a number of government agencies we developed a set of indicators of community strength. These focused broadly on aspects relating to the creation of social networks, the degree of community participation, people's perceptions of safety in their own community, their ability to get help when needed, and local area amenity.

This data has now been collected in 10 annual, statewide surveys that form part of a broader Victorian population health survey, which is conducted by the Department of Human Services. Also, three surveys at a local governmentarea level were conducted in 2004, 2006, and 2008. Through the data obtained we have been able to understand the importance of: strong personal networks, how these networks generate benefits for both individuals and communities; governance in sustaining social capital; and, of course, the high value that people place on easy access to a range of community facilities.

One finding of our work, not surprisingly, is that different communities have different strengths and areas for improvement. This led the Department to introduce a range of programs that facilitated local communities' involvement in community planning and their subsequent access to investment opportunities through a number of grant programs funded by the Department and other agencies.

Caroline Springs, on the outskirts of Melbourne, is a region in which the department has undertaken particular work. There, we established a partnership between the government, the local shire (Melton Shire), and a developer (Delfin Lend Lease) to ensure the timely delivery of community infrastructure and its joint use. Throughout this process we gained a sense of what that partnership could mean for the cohesiveness and strength of the local community.

The project had well-designed performance indicators, and community surveys of the partnership — which were undertaken in 2005 and again in 2007 - represented another way of monitoring the efficacy of the partnership. The surveys showed significant improvement in relation to the performance indicators. Over time we saw an increase in attendance at community events, improved access to facilities and services, and a clear view that Caroline Springs was an active community - albeit a new one - where people got involved in local issues.

Compared with other places with similar demographics, more people in Caroline Springs experienced their community as a friendly and helpful one, and believed it to be a special place in which to live, and that there were 
opportunities for people to have a say and to get involved. These indicators of community satisfaction are now widely used by a range of Victorian government departments, by local governments in their council plans, and by a range of other community based organisations.

And yet, in our role of overseeing local government, we are aware of the potential confusion arising from overlapping roles and responsibilities between the various tiers of government. Two issues - the division of responsibility between state and local government and the responsibility of elected members to effectively raise revenue - raise existential questions about our system of government.

That said, in Victoria in the 1990s, when there was a strong regime of ratecapping in place following reforms to local government, the prevailing mood was that it was a very blunt tool. Certainly, the councils proclaimed that it did not effectively enable them to transfer risk for underinvestment to the state government, because the state government was stopping them raising appropriate levels of revenue.

When that restraint was taken off, over the last 10 years or so, what we have seen is local government rates increase at a level that is probably three or four percentage points a year above the rate of inflation. This is an issue that concerned the previous Labor government under John Brumby, and it is one that will become a concern for the current Coalition government under Ted Baillieu.

It is interesting that we are only now beginning to detect community resistance to rate increases and, even though we have had the data for some time, there has previously not been a concerted attempt to explore this. It is likely that, over time, the Baillieu government will attempt it, by meshing the satisfaction data with the rate increase data.

I maintain a pragmatic approach to resourcing questions. There are issues about the responsibility of councillors to set their own level of resourcing. And council rates, which can form a significant part of any council's budget, are taxes that many residents simply pay year-on-year. Unless there are pressures from other sources, these amounts do creep up. For example, rates have increased at a much faster rate than the cost of gas and electricity over that period of time, and yet the cost of utilities seems to be at the forefront of public debate, whilst rate increases have not been.

In 2002, the Steve Bracks Labor government brought out an overarching strategic framework called Growing Victoria Together, and a number of our indicators were selected as measures of progress against one of the core objectives, which was building cohesive communities. The indicators were also instrumental in 
shaping the previous government's social policy framework called A Fairer Victoria, from its inception in 2005 through to 2010. Through the measures which were constantly surveyed over that period of time, the government was able to see an increase in general community satisfaction with the level of community infrastructure provided, the level of satisfaction rising from 80 per cent in 2006 to 85 per cent in 2008.

The A Fairer Victoria framework caused a decline in the proportion of Victorians who were members of a group in their local communities, albeit a relatively small decline. I think this decline largely reflects both national and international trends but, interestingly, we saw an increased proportion across the state of people who believed that they had an opportunity to have a say in matters affecting them. Between 2005 and 2010 this percentage increased from 36 per cent to 42 per cent - even though this is still a low figure.

In summary, the indicators have provided a guide for community planning and action to address local issues, a rationale for government intervention to improve connections in local communities, and an ongoing way, over that period from 2005 to 2010, of measuring whether those interventions were effective.

Let me now turn to my second example, which is an annual community satisfaction survey of local government performance. This has been the responsibility of our local government division since the surveys began in the late 1990s. Initially funded by the Victorian state government, the esteem in which local councils now hold these surveys is reflected in the fact that they now fully fund it. The Department continues, however, to oversee its production, conduct the analysis of the results, and release information publically.

A minimum of 350 telephone interviews are conducted in each municipality, resulting therefore in 28,000 interviews across the state, which in turn provides some insightful feedback. The Victorian Population Health Survey, to which I referred earlier, actually conducts 450 interviews per local government authority, which increases the number of interviews conducted statewide to over 30,000 .

Respondents to the council survey are asked questions to determine their level of satisfaction with the performance of their councils across a whole range of service areas, including their advocacy role, customer contact and community engagement, as well as assessing the council's overall performance. A statewide research result summary, 'Local Government in Victoria', is published annually. This provides average performances for all the councils, and comparative results for five groups of councils, inner and outer metropolitan councils, rural cities and regional centres, and large and small shires. Individual reports are also provided for each council on their own performance. 
This survey has allowed us to measure the performance of council's in Victoria over time. Since 1998 we have seen an improvement of eight percentage points in the percentage of respondents who rate their councils as excellent, good, and adequate, from (69 to 77 per cent). And it also tells us how they are performing in particular activities. For example, the 2011 results revealed that residents thought their councils do reasonably well in delivering health and human services. In fact, a staggering 89 per cent think they perform well in that area, and in the area of recreational facilities, 81 per cent. This sentiment was not shared when residents were asked about how well their council was maintaining their local roads and footpaths. And it is disappointing to note that, generally, satisfaction with the broader role of councils in community engagement has declined from in the mid 1970s, in the early years of the survey, to 67 per cent this year.

But the survey does provide rich data for state government, local councils and, of course, residents. It enabled councils to communicate their achievements to their community, and to compare their performance against other councils. And I cannot emphasise enough the importance of that comparative opportunity: councils always look one across the other, and are sensitive about their performance as compared with a similar cohort.

It also provides state government with data to assess council performance and trends over time, and identify whether regulatory or policy intervention might be required. And, perhaps most importantly, it provides residents with information that they can use to lobby for service improvements, or indeed change their elected representatives.

Surveys are one way of collating the data and establish the evidence about what communities need and value. The surveys we do, the data we provide, and the community engagement processes we undertake are the tools we use to: try to understand what people think and want; to identify how government policies, programs, and systems are working; and to provide input into policy development and service and system improvements.

These engagement tools fall into four categories. Firstly, the gathering of the evidence through surveys and research (and I cannot emphasise enough the importance of the factor of time in conducting the surveys and collating the responses). The local government survey has been taking place for 12 years, and there is, as a result, a rich source of data to draw upon. The surveys that we have done in relation to the first set of indicators have, in various forms, been going on now for close to nine years. 
Second is the act of taking the department into the community, through the work that departmental staff do in local communities, performing a brokering and facilitating role, and encouraging the formation of partnerships between local organisations, councils, and residents.

Third is the provision of opportunities for members of the community to be engaged should they wish to be. This is done through forums, such as our regular community meetings, where senior departmental staff meet directly with the local community. As these are openly structured meetings, anybody who wants to come is welcome. Such occasions enable us to hear directly, unmediated by others, the views and experiences of people.

While the planning systems vary from state to state, I think one of the characteristics of them across the country is the formal process that one must go through to comment on changes to planning schemes, or the possibility of particular sorts of development. They are rigid and inflexible and generally lack transparency.

If I had a particular wish, it would be to embed into the Victorian planning system a range of requirements for councils to be more open and engaging, and to do this at the front end, when they are amending planning schemes, rather than to do it through a relatively passive advertising process. I believe that, over time, this would encourage more people to have their say.

And yet, active citizen engagement is not a hallmark of Australia's political and civic culture; the prevailing assumption that people do not want to get involved in the political and civic process ought to be interrogated.

Finally, our fourth engagement tool is a substantial investment in capacity building. This involves supporting community members to obtain the necessary skills to participate in community organisations. To me, these different types of engagements are essential elements of what good public administration is about. But I often reflect on how rarely these elements are seen as core activities of government agencies.

There is, however, always room for improvement. The next five years will see variation in our focus on the intensive face-to-face engagement that has dominated the Department's recent connection with community. The increased use of social media has the potential to allow us to continue this work; other Victorian agencies are already maximising its potential. 